\title{
Structural Durability of Stiffened Composite Shells
}

Levon Minnetyan and James M. Rivers

Clarkson University

Potsdam, New York

Pappu L.N. Murthy and Christos C. Chamis

National Aeronautics and Space Administration

Lewis Research Center

Cleveland, Ohio

Presented at the 33rd Structures, Structural Dynamics and Materials Conference cosponsored by AIAA, ASME, ASCE, AHS, and ASC Dallas, Texas, April 13-15, 1992 
Keywords: composites, computational simulation, damage, degradation, durability, fracture, stiffened shells, structural integrity

STAR Category 24 


\section{Table of Contents}

Title Page

Keywords

STAR Category

Table of Contents

Abstract

Nomenclature

Introduction

The CODSTRAN Methodology

Stiffened Shell Panel

Summary and Conclusions

Page

i

ii

ii

iii

1

1

2

3

5

References

10

Tables 1-9

12

List of Figure Captions

13-17

18

Figures 1-12 attached sequentially 


\title{
STRUCTURAL DURABILITY OF STIFFENED COMPOSITE SHELLS
}

\author{
Levon Minnetyan* and James M. Rivers ${ }^{\dagger}$ \\ Clarkson University, Potsdam, New York 13699-5710 \\ Pappu L. N. Murthy ${ }^{\ddagger}$ and Christos C. Chamis ${ }^{\S}$ \\ National Aeronautics and Space Administration \\ Lewis Research Center, Cleveland, Ohio 44135
}

\begin{abstract}
The durability of a stiffened composite cylindrical shell panel is investigated under several loading conditions. An integrated computer code is utilized for the simulation of load induced structural degradation. Damage initiation, growth, and accumulation up to the stage of propagation to fracture are included in the computational simulation. Results indicate significant differences in the degradation paths for different loading cases. Effects of combined loading on structural durability and ultimate structural strength of a stiffened shell are assessed.
\end{abstract}

\section{Nomenclature}

$\sigma_{\ell 11}$ - ply longitudinal stress

$\sigma_{\ell 22}$ - ply transverse stress

$\sigma_{\ell 33}$ - ply normal stress

$\sigma_{\ell 12}$ - ply in-plane shear stress

$\sigma_{\ell 23}$ - ply out-of-plane shear stress

"Associate Professor, Department of Civil and Environmental Engineering

${ }^{\dagger}$ Graduate Student, Department of Civil and Environmental Engineering

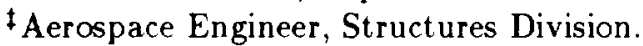

${ }^{\S}$ Senior Aerospace Scientist, Structures Division. 
$\sigma_{\ell 13}$ - ply out-of-plane shear stress

$\sigma_{\ell 11 T}$ - ply longitudinal tensile stress

$\sigma_{\ell 11 C}$ - ply longitudinal compressive stress

$\sigma_{\ell 22 T}$ - ply transverse tensile stress

MDE - modified distortion energy failure criterion

$R$ - radius of cylindrical shell

$\mathrm{RR}$ - delamination due to relative rotation

\section{Introduction}

The use of advanced fiber composites in aerospace structures has significantly increased in recent years due to the design flexibilities that are inherently present in laminated composites. Composite structures lend themselves to structural tailoring, bringing also the advantages of their light weight, high strength, and controllable dielectric and electromagnetic properties. In common aerospace applications such as advanced aircraft fuselage and wings, composite structures are expected to withstand many possible combinations of loads. For the certification of composite aircraft, extensive structural testing is necessary under all possible loading conditions/combinations. The standard design configuration to service the required loads with sufficient structural strength and stability is a composite shell structure that is stiffened by an integral structural framework. Along the axial direction of a cylindrical shell, composite stringers are used to provide additional strength and stiffness under axial tension, compression, and bending. Stringer stiffeners also contribute to the shear strength of the stiffened shell by providing stability to the composite outer shell which resists the shear loading. However, the degradation of stringer webs under shear loading due to damage initiation by shear distortion of the stiffened shell is a fundamental design consideration. The objective of this paper is to present a computational tool that has been developed to examine the durability of stiffened composite shells via the simulation of damage growth, progression, and evaluation of structural fracture resistance under loading.

The predictions of damage initiation, damage growth, and propagation to fracture are important in evaluating the load carrying capacity, safety, and reliability of composite structures. Quantification of the structural fracture resistance is also fundamental for evaluating the durability/life of composite structures. The most effective way to obtain this quantification 
is through integrated computer codes which couple composite mechanics with structural analysis and with fracture mechanics concepts. The COmposite Durability STRuctural ANalysis (CODSTRAN) computer code ${ }^{1}$ has been developed for this purpose. The simulation of progressive fracture by CODSTRAN has been validated to be in reasonable agreement with experimental data from tensile tests. ${ }^{2}$ Recent additions to CODSTRAN have enabled investigation of the effects of composite degradation on structural response, ${ }^{3}$ composite dam-

age induced by dynamic loading, ${ }^{4}$ composite structures global fracture toughness, ${ }^{5}$ effect of the hygrothermal environment on durability, ${ }^{6}$ and structural damage/fracture simulation in composite thin shells subject to internal pressure. ${ }^{7}$ To date, presented computational simulation capabilities have consisted of composite structures in the form of composite panels and unstiffened shells. To evaluate the durability of stiffened shells in which the composite shell and framework constitute a unified structure, it is necessary to represent a combined outer shell and stringer framework structure in the computational model. The objective of this paper is to present a recently developed capability in CODSTRAN to simulate the durability, damage initiation, growth, accumulation, and progression in stiffened composite shells.

\section{The CODSTRAN Methodology}

CODSTRAN is an integrated, open-ended, stand alone computer code consisting of three modules: composite mechanics, finite element analysis, and damage progression modelling, respectively. The overall evaluation of composite structural durability is carried out in the damage progression module ${ }^{1}$ that keeps track of composite degradation for the entire structure. The damage progression module relies on $\mathrm{ICAN}^{8}$ for composite micromechanics, macromechanics and laminate analysis, and a finite element analysis module ${ }^{9}$ with anisotropic thick shell analysis capability to model laminated composites for global structural response. A convenient feature of the utilized finite element module is that structural properties are input and generalized stress resultants are output at the nodes rather than for the elements.

Figure 1 shows a schematic of the computational simulation cycle in CODSTRAN. The ICAN composite mechanics module is called before and after each finite element analysis. Prior to each finite element analysis, the ICAN module computes the composite properties from the fiber and matrix constituent characteristics and the composite layup. The laminate 
properties may be different at each node. The finite element analysis module accepts the composite properties that are computed by the ICAN module at each node and performs the analysis at each load increment. After an incremental finite element analysis, the computed generalized nodal force resultants and deformations are supplied to the ICAN module that evaluates the nature and amount of local damage, if any, in the plies of the composite laminate. Individual ply failure modes checked in CODSTRAN include the failure criteria associated with the negative and positive limits of the six ply-stress components $\left(\sigma_{\ell 11}\right.$, $\sigma_{\ell 22}, \sigma_{\ell 33}, \sigma_{\ell 12}, \sigma_{\ell 23}, \sigma_{\ell 13}$ ), a modified distortion energy (MDE) or combined stress strength criterion, and interply delamination due to relative rotation (RR) of the plies. ${ }^{8}$

CODSTRAN is able to simulate varied and complex composite damage mechanisms via evaluation of the individual ply failure modes and associated degradation of laminate properties. In general, the type of damage growth and the sequence of damage progression depend on the composite structure, loading, material properties, and hygrothermal conditions. The rate of overall damage growth with work done during composite degradation is used to evaluate the propensity of structural fracture with increasing loading.

For the purpose of the present discussion, the following terminology is used to describe the various stages of degradation in the composite structure: (1) damage initiation refers to the start of damage induced by loading; (2) damage growth is the progression of damage from the location of damage initiation to adjacent regions; (3) damage accumulation is the increase in the amount of damage in the damaged region with additional damage modes becoming active; (4) nodal fracture is a through-the-thickness fracture at a node because of major tensile or compressive failures in all plies of the laminate. Nodal fracture is a characteristic antecedent of rapid damage propagation toward structural fracture.

At any stage of damage progression, if there is a sufficiently high level of structural resistance to damage progression under loading, the structure is stable with regard to fracture. The corresponding state of structural damage is referred to as stable damage. On the other hand, if damage progression does not encounter significant structural resistance, it corresponds to an unstable damage state. Unstable damage progression is characterized by very large increases in the amount of damage due to small increases in loading; whereas, during stable damage progression the amount of increase in damage is consistent with the increase in loading. Nodal fracture typically precedes the final unstable damage propagation stage that results in ultimate structural collapse or fracture. 
The generalized stress-strain relationships for each node are revised according to the composite damage evaluated by the ICAN module after each finite element analysis. The model is automatically updated with a new finite element mesh and properties, and the structure is reanalyzed for further deformation and damage. If there is no damage after a load increment, the structure is considered to be in equilibrium and an additional load increment is applied. Figure 2 shows a schematic of CODSTRAN damage tracking, expressed in terms of a load-displacement relationship. Point 1 represents the last equilibrium state before initial damage. When the structure is loaded by an additional load increment to point 2, ply failure criteria indicate damage initiation. At this stage CODSTRAN degrades the composite properties affected by the damage, reconstitutes a new computational model with updated finite element mesh and material properties, and reanalizes the structure under the same load increment to reach point 3 . However, at point 3 , composite ply failure criteria indicate additional damage. Accordingly, structural properties are further degraded and analysis is repeated under the same load increment to reach point 4 . There is no further damage at point 4 , because the structure is now in equilibrium with the external loads. Subsequently, another load increment is applied leading to point 5 with possible damage growth and accumulation. In the computational simulation cases presented in this paper, analysis is stopped when commencement of the damage propagation phase is indicated by a nodal fracture. Nodal fracture is predicted when major principal failure criteria are met for all plies at a node. After nodal fracturing, the composite structure is anticipated to enter a final damage propagation stage that leads to ultimate structural fracture or collapse.

\section{Stiffened Shell Panel}

The demonstration example for this paper consists of a stiffened composite cylindrical shell panel with imposed boundary conditions to represent the behavior of a segment of the entire cylindrical shell, as depicted in Figure 3, subjected to 1) axial tension, 2) axial compression, 3) shear, 4) internal pressure (with the associated axial and hoop generalized stresses), and combinations of these four fundamental loads. The composite system is made of Thornel-300 graphite fibers in an epoxy matrix (T300/Epoxy). The outer shell laminate consists of fifty $0.127 \mathrm{~mm}$. (0.005 in.) plies resulting in a composite shell thickness of $6.35 \mathrm{~mm}$. (0.25 in.). The laminate configuration for the outer shell is $\left[90 /\left([90 / \pm 15 / 90]_{s}\right)_{3}\right]_{s}$. The $90^{\circ}$ plies are in the hoop direction and the $\pm 15^{\circ}$ plies are oriented with respect to the axial direction of 
the shell. The cylindrical shell panel has a constant radius of curvature of $\mathrm{R}=2.286 \mathrm{~m}$. (90 in.). The subtended angle of the shell panel arc is $\theta=30^{\circ}$ or $\pi / 6$, resulting in an arc length of $\mathrm{s}=\mathrm{R} \theta=1.197 \mathrm{~m}$. (47.12 in.). The length of the stiffened panel along the shell axis is 1.219 m. (48 in.).

The stiffener elements are made from the same T300/Epoxy composite as the outer shell. The stiffeners are glued to the outer shell at all surfaces of contact. The adhesive properties between the outer shell and the stiffeners are the same as those of the Epoxy matrix. In general, the stiffener laminate configuration consists of 20 plies of $\left([ \pm 45]_{s}\right)_{5}$ composite structure for the webs and for the continuous toe elements that attach to the outer shell. Stiffener flanges or caps have an additional 30 plies of $0^{\circ}$ (axial) fibers. Figure 4 indicates laminate configurations in the structural elements of the stiffened shell.

The finite element model contains 168 quadrilateral thick shell elements, of which 96 are utilized to represent the outer shell, as indicated by the grid lines shown in Figure 3 . The remaining 72 elements are used to represent the stiffener webs and flanges.

Because the finite element properties and resulting generalized stresses are specified at each node, duplicate nodes are needed where there are discontinuities in the finite element properties. Duplicate nodes have the same degree of freedom coordinates but allow the definition of different structural properties. Figure 5 shows typical duplicate nodes along a representative hoop segment of the shell panel. At points where duplicate nodal definitions are required, the node with the smallest number is designated as the master node and the other nodes are designated as the slave nodes that are assigned exactly the same degree of freedom coordinates as the master node. In Figure 5 the subscript $m$ after a node number indicates a master node and the subscript $s$ indicates a slave node. In Figure 5 separate points are noted to distinguish the master and slave nodes that are assigned the same degree-of-freedom coordinates. In the actual finite element model, however, corresponding master and slave nodes coincide at a point. The finite element model for the investigated stiffened shell panel requires 333 nodes of which 171 are master nodes and the remaining 162 are slave nodes.

Loading on the stiffened shell panel that is of interest for design purposes may include one or more of the following components: 1) Axial Tension or 2) Axial Compression, 3) Shear, and 4) Internal Pressure. Composite structural durability is first investigated under each one of these four loading cases. The four fundamental loading cases are illustrated in Figure 6 . In addition, four combined loading cases are also investigated as follows: 5) Axial Tension and 
Shear, 6) Axial Compression and Shear, 7) Axial Tension and Shear under Internal Pressure, and 8) Axial Compression and Shear under Internal Pressure. Boundary conditions, as shown in Figure 3, are the same for all eight loading cases. In each case, computational simulation of structural durability under loading is carried out through the stages of damage initiation, damage growth, and damage accumulation, up to the stage of damage propagation.

1) Axial Tension-Axial loading is applied along the positive $y$ axis on one face of the stiffened shell panel. The share of axial loading on the stiffeners is proportional to the relative axial stiffness of the stiffener elements as compared to the outer shell. Table 1 summarizes damage progression highlights for this case. The axial load is given per unit length of the circumferential arc segment of the stiffened shell panel.

2) Axial Compression- Axial compression loading is applied using the same loading configuration as in axial tension, but the loads are applied in the opposite sense. Table 2 summarizes damage progression for the axial compression case.

3) Shear-Table 3 summarizes damage progression for the shear loading case. Shear loading is the most critical with regard to damage initiation in the stiffener webs by in-plane shear failures. For the examined composite structure and geometry, the damage initiation load is under one tenth of the nodal fracture node. These results indicate that structural durability performance under shear loading is an important design consideration and that shear loading effects need be carefully considered in the design of stiffened composite shells. Stiffener web thickness and laminate structure as well as the stiffener profile/geometry are important design parameters.

4) Internal Pressure- A gradually increasing pressure is applied to the outer shell from its interior or concave side of the panel. Uniformly distributed hoop and axial tensions are also applied to the cylindrical panel, to simulate loads on a closed-end cylindrical pressure vessel. Accordingly, axial tension in the shell wall is half that developed in the hoop direction. Table 4 summarizes three significant damage stages during pressurization. Durability analysis indicates that pressurization alone is not a critical design load for this composite structure since the damage initiation pressure of $1.68 \mathrm{MPa}(259 \mathrm{psi})$ is approximately twenty times the static pressurization service load for typical aircraft structures.

5) Axial Tension and Shear- The first load increment consists of $17.5 \mathrm{KN} / \mathrm{m}$ (100 lbs/in.) shear and $473 \mathrm{KN} / \mathrm{m}(2,700 \mathrm{lbs} / \mathrm{in}$.) tension. The relative magnitude of the shear component 
of loading is selected according to the expected service loading combinations indicated in the design of the stiffened shell example. The ratio of shear to axial tension loading is kept constant at $1 / 27$ as the loading is increased. Table 5 summarizes the damage initiation, progression, and nodal fracture stages under this loading. The damage initiation load and the fracture load are reduced due to combined loading. The overall degradation pattern is similar to that of shear loading examined in Case 3 above.

6) Axial Compression and Shear-This is similar to case 5, except that the axial loading component is compressive rather than tensile. As it was in case 5 , the effect of combined loading is to reduce the ultimate structural durability of the stiffened composite panel. Results under axial compression plus shear loading are summarized in Table 6 in terms of the axial compression component of the load. The ratio of shear loading per unit length of boundary, to axial compressive loading per unit length of the hoop side of the panel is $1 / 27$ for all load levels. The axial compression and shear components of loading are as shown in Figure 6. In relation to axial compression loading described in case 2, the nodal fracture load is reduced by 24 percent. The damage initiation load is not significantly affected. However, the initial damage mode now includes in-plane shear failures in the stringer webs. As loading is increased, damage accumulation in stringer webs results in nodal fractures in the web elements.

7) Axial Tension and Shear with Pressurization- The first load increment consists of 17.5 $\mathrm{KN} / \mathrm{m}(100 \mathrm{lbs} / \mathrm{in}$.) shear and $473 \mathrm{KN} / \mathrm{m}(2,700 \mathrm{lbs} /$ in.) tension, and also $100 \mathrm{KPa}(1.4 \mathrm{psi})$ internal pressure with the associated hoop and axial tensions also added. The load ratios are kept constant as the loading is increased. Results are described in Table 7. Degradation patterns are similar to those of case 5 . The effect of pressurization is to increase the loading level corresponding to nodal fracture.

8) Axial Compression and Shear with Pressurization-Results are summarized in Table 8. Loading is similar to case 7 except that axial loading is compressive rather than tensile. Degradation is similar to case 6 . The nodal fracture load is increased with pressure as in case 7 .

Figure 7 shows the load versus damage curves for axial tension only, axial tension with shear, and axial tension with shear under pressurization (cases 1, 5, and 7, respectively). The scalar damage variable, shown on the abscissa, is derived from the total volume of the composite material affected by the various damage mechanisms. Computation of the shown 
scalar damage variable has no interactive feedback on the detailed simulation of composite degradation. The curves end when nodal fracture is predicted. When shear is added to axial tension, damage initiation and progression to fracture occur under a lower load. The amount of damage at the time of fracture is less than that corresponding to axial tension only. At the initial stages of structural degradation, pressurization does not affect damage progression. However, nodal fracture requires a considerably higher load compared to the tension plus shear case.

Figure 8 shows the structural response degradation with endured tensile loading. Structural response properties are represented by the first natural frequency of the stiffened shell panel and the fundamental buckling load under external pressure. On the ordinate, $F / F_{0}$ represents the ratio of damaged natural frequency to undamaged natural frequency. Similarly, $\mathrm{B} / \mathrm{B}_{0}$ represents the ratio of damaged buckling load to undamaged buckling load. At the time of local fracture, Figure 8 indicates that the fundamental buckling load is reduced by 12 percent and the first natural frequency is reduced by 8 percent as compared to those of an undamaged stiffened shell panel.

Figure 9 shows the load to damage relationships for axial compressive load, axial compression with shear, and axial compression with shear under pressurization (cases 2, 6, and 8, respectively). Compressive load levels for damage initiation and progression are lower compared to the tensile load cases due to material properties as well as structural effects. Effect of the shear loading component is to reduce the load levels that cause damage initiation and progression. Pressurization does not play an important role at the start of damage. However, the nodal fracture load is raised considerably due to the stabilizing effect of internal pressure.

Figure 10 shows contours for the $z$ component of nodal displacements under $2.0 \mathrm{MN} / \mathrm{m}$ axial compressive load, immediately before fracture. The global $\mathrm{z}$ axis is in the outward normal direction of the shell at the center of the panel. Figure 10 indicates that the outer shell bulges out at the unstiffened regions under compression.

Figure 11 shows the load versus damage curves for shear only and the shear component of the combined loading cases. The overall damage progression curves under shear only and combined loading are quite different. However, it is significant that the initial stages of damage progression are similar, indicating the influence of the shear loading component in establishing the structural degradation characteristics under combined loading. 
Figure 12 shows pressure and the pressure component of combined loading versus damage progression. Pressure does not play a major role in the damage progression under combined loading as the pressurization component is less than 10 percent of the damage initiation load under pressure only.

Table 9 summarizes the damage progression sequence for all eight loading cases, indicating the structural elements affected during the damage initiation, growth, progression, and fracture stages. It is important to note that for any structure the damage progression sequence depends on fiber orientations and laminate structure as well as loading. The computational capability demonstrated in this report is useful for answering design questions with regard to durability as well as stiffness and strength for alternative laminate configurations.

\section{Summary and Conclusions}

The behavior of laminated composite structures under loading is rather complex, especially when possible degradation and damage propagation to fracture is to be considered. Because of the numerous possibilities with material combinations, cure temperature, service environment, composite geometry, ply orientations, and loading conditions, it is essential to have an effective computational capability to predict the behavior of composite structures for any loading, geometry, composite material combinations, and boundary conditions. The predictions of damage initiation, growth, accumulation, and fracture are important in evaluating the load carrying capacity and reliability of composite structures.

The present investigation was limited to a composite stiffened shell panel under static loading. Other cases can be investigated by CODSTRAN; including fatigue, shock, impact, blast pressure, general dynamic loading, and combinations of these loads. The presented results are computed assuming that the composite structure is at room temperature and contains no moisture. The effects of other hygrothermal environments with higher or lower temperatures and some moisture can be included in any CODSTRAN investigation. Damage growth and fracture propagation in other types of structures such as variable thickness composites, hybrid composites, thick composite shells, and structures or components fabricated from homogeneous materials can also be simulated. The relationship between composite damage and structural response properties such as natural frequencies, vibration modes, buckling loads and buckling modes can be computed by CODSTRAN for any type of structure. A complete cylindrical shell or a shell with any other shape with any geometry of stiffeners may 
be investigated. The complexity of the computational model can be adjusted depending on the stage of progress in the composite structural design process.

The significant results derived from this investigation in which CODSTRAN (COmposite Durability STRuctural ANalysis) is used to evaluate damage initiation, growth, and progression in a stiffened composite shell are as follows:

1. Computational simulation, with the use of established composite mechanics and finite element modules, can be used to predict the influence of various loads on the safety and durability of composite structures.

2. CODSTRAN adequately tracks the damage initiation, growth, accumulation, and progression up to fracture for stiffened composite shells under axial tension, compression, shear, internal pressure, and combinations of these loads.

3. For stiffened shells, combined loading effects are significant in the overall structural durability behavior. Shear loading is the most significant with regard to the durability of stiffened composite shells. A relatively small shear component may affect and control the damage initiation and progression patterns under combined loading. At the presence of shear, damage initiation and progression is by in-plane shear failures in the webs of the stringers. The presence of shear reduces the structural durability of the example stiffened composite shell when combined with any other loading.

4. Pressurization plays a minor role in the structural durability at the initial stages of degradation under combined loading. The effects of pressurization are more pronounced at the advanced stages of structural degradation. If pressurization is added to axial and shear loads, nodal fracture is delayed for the investigated stiffened composite shell panel.

5. The demonstrated procedure is flexible and applicable to all types of constituent materials, structural geometry, and loading. Hybrid composites and homogeneous materials, as well as binary composites can be simulated.

6. In-service structural health monitoring is facilitated by the prediction of damage initiation and progression mechanisms and the resulting deviations from normal structural response. 
7. The CODSTRAN methodology incorporates a new global and integrated approach to structural integrity/durability assessment for design investigations.

Acknowledgment- The participation of the first two authors in this research was sponsored by NASA-Lewis Research Center under grant NAG-3-1101.

\section{REFERENCES}

1. C. C. Chamis and G. T. Smith, "Composite Durability Structural Analysis," NASA TM-79070, 1978.

2. T. B. Irvine and C. A. Ginty, "Progressive Fracture of Fiber Composites," Journal of Composite Materials, Vol. 20, March 1986, pp. 166-184.

3. L. Minnetyan, C. C. Chamis, and P. L. N. Murthy, "Structural Behavior of Composites with Progressive Fracture," NASA TM-102370, January 1990, 18 pp.

4. L. Minnetyan, P. L. N. Murthy, and C. C. Chamis, "Progression of Damage and Fracture in Composites under Dynamic Loading," NASA TM-103118, April 1990, 16 pp.

5. L. Minnetyan, P. L. N. Murthy, and C. C. Chamis, "Composite Structure Global Fracture Toughness via Computational Simulation," Computers 6 Structures, Vol. 37, No. 2, pp.175-180, 1990

6. L. Minnetyan, P. L. N. Murthy, and C. C. Chamis, "Progressive Fracture in Composites Subjected to Hygrothermal Environment," Proceedings of the 32nd SDM Conference (Part 1), Baltimore, Maryland, April 8-10, 1991, pp. 867-877.

7. L. Minnetyan, C. C. Chamis, and P. L. N. Murthy, "Damage and Fracture in Composite Thin Shells,"

NASA TM-105289, November 1991

8. P. L. N. Murthy and C. C. Chamis, Integrated Composite Analyzer (ICAN): Users and Programmers Manual, NASA Technical Paper 2515, March 1986.

9. S. Nakazawa, J. B. Dias, and M. S. Spiegel, MHOST Users'Manual, Prepared for NASA Lewis Research Center by MARC Analysis Research Corp., April 1987. 

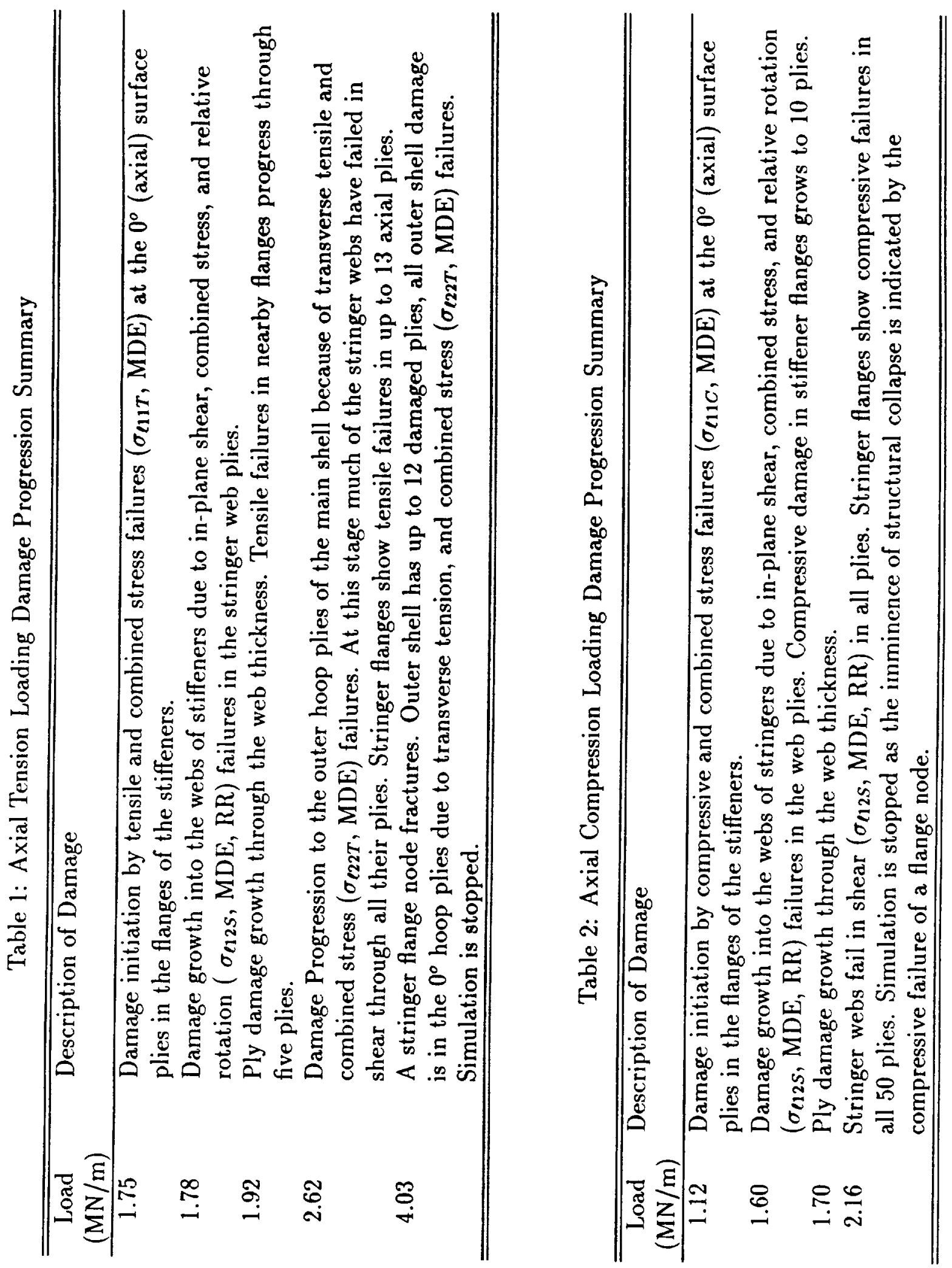

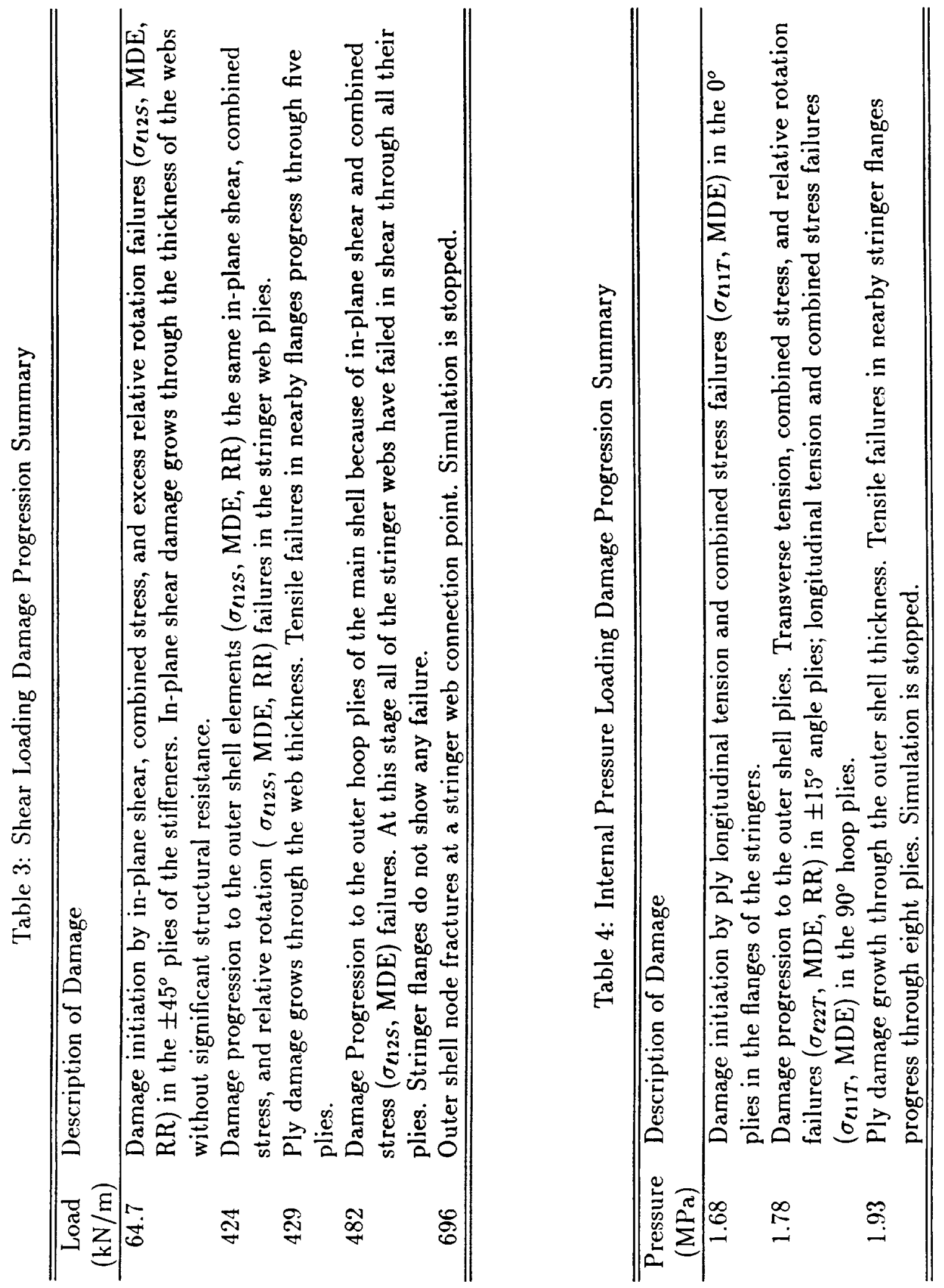

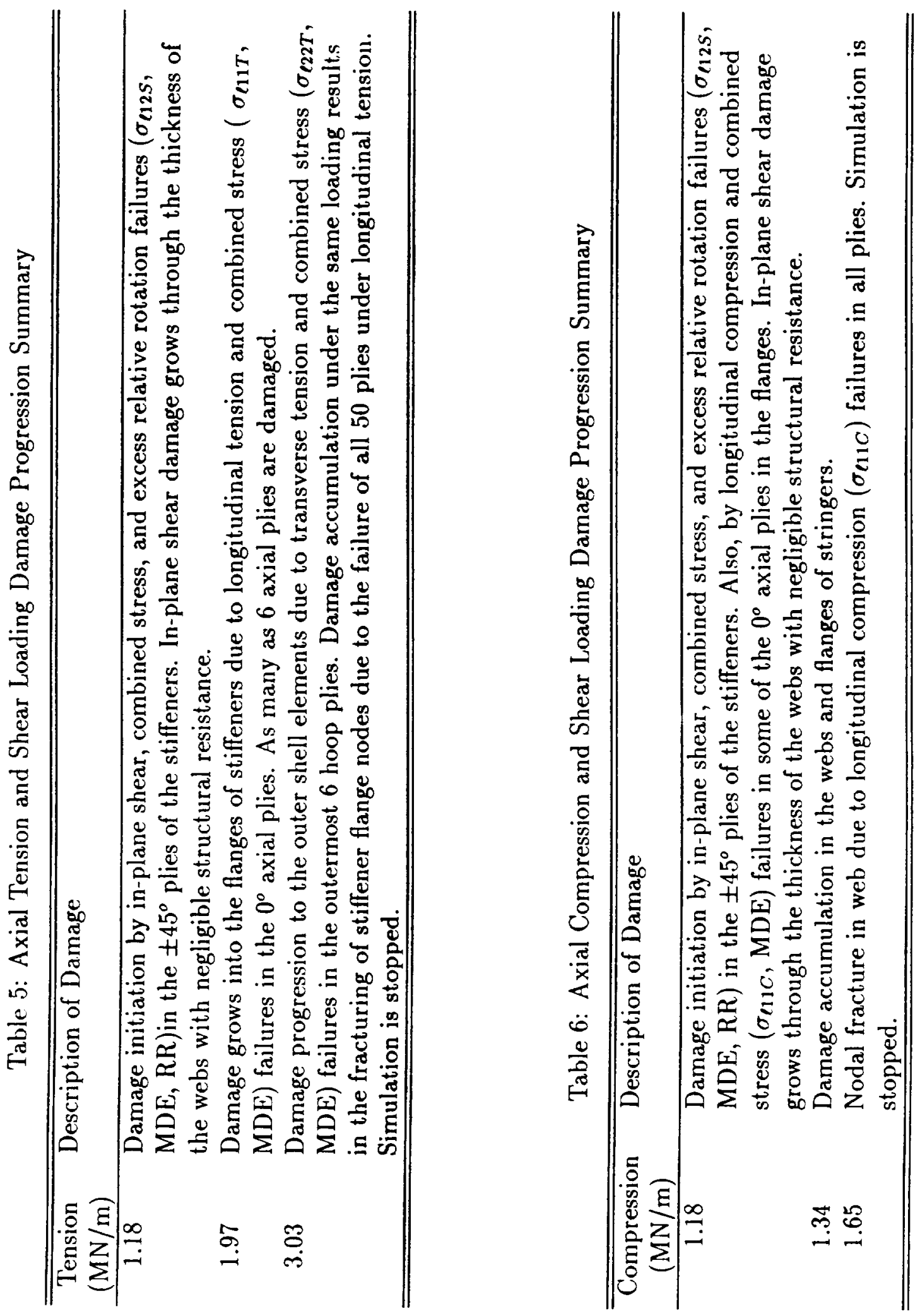

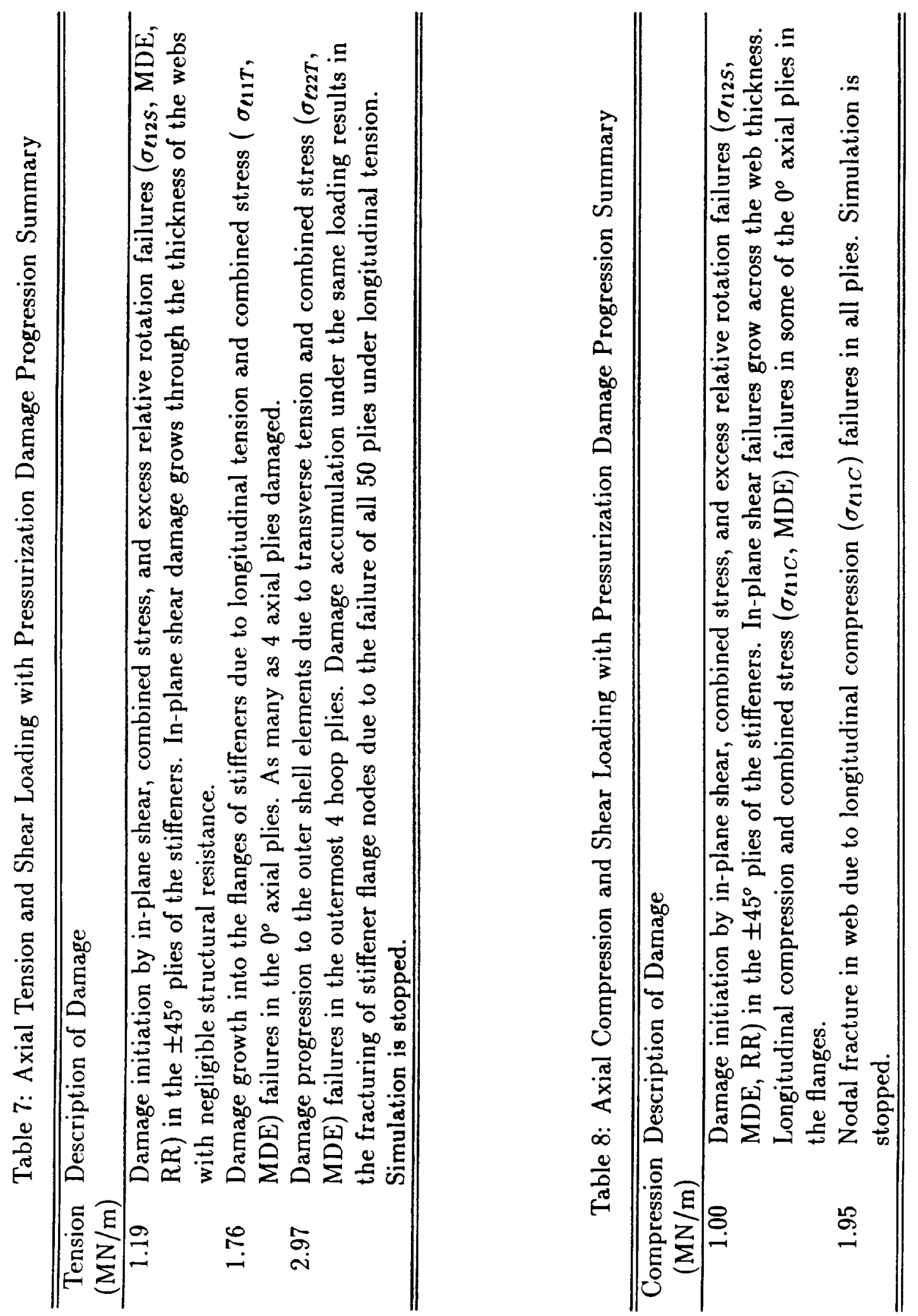

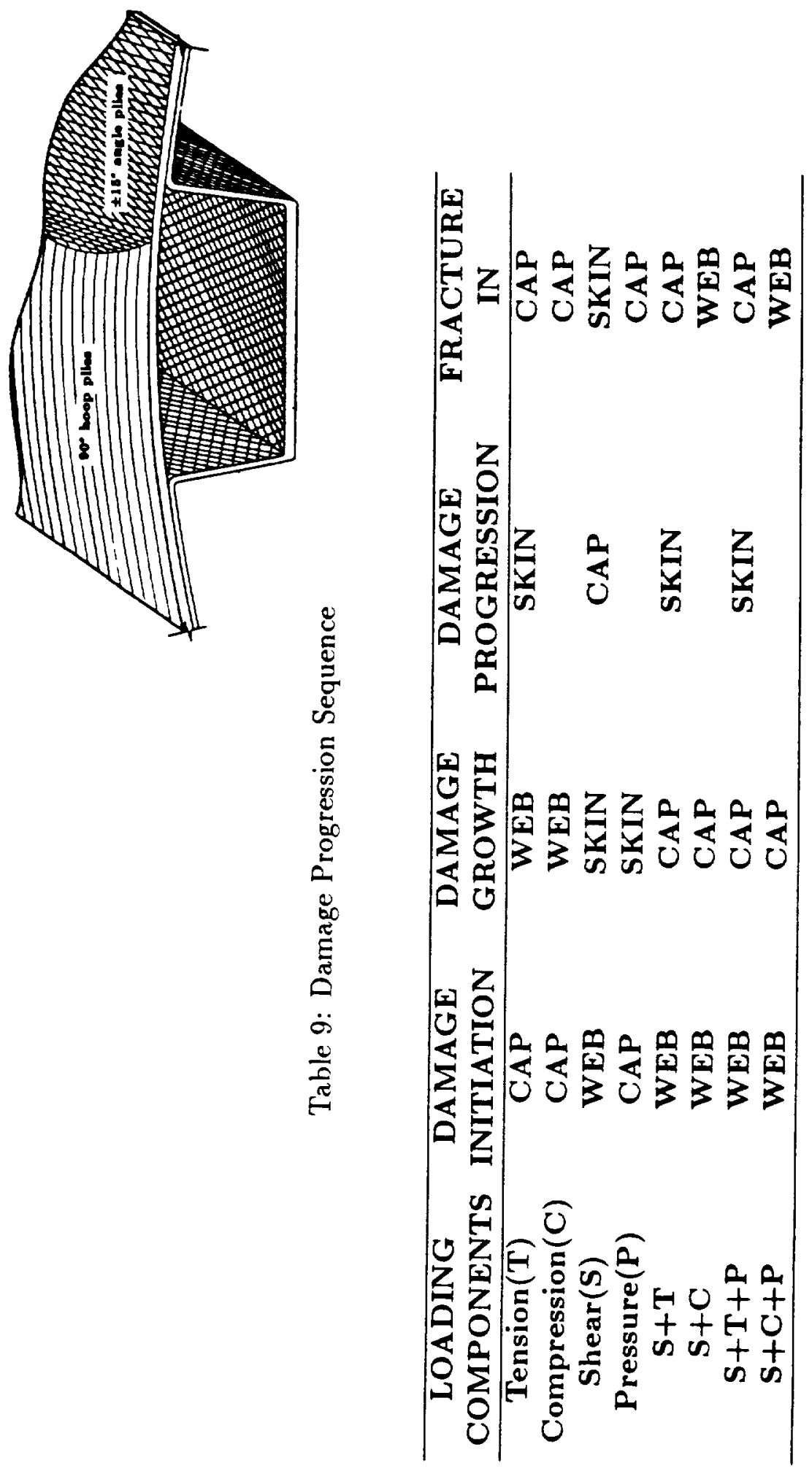


\section{LIST OF FIGURE CAPTIONS}

Figure 1 CODSTRAN Simulation Cycle

Figure 2 CODSTRAN Damage Tracking

Figure 3 Stiffened Composite Cylindrical Shell Panel

T300/Epoxy Laminate: Skin $\left[90 /\left([90 / \pm 15 / 90]_{s}\right)_{3}\right]_{s}$;

Web and toe $([ \pm 45] \mathrm{s})_{5} ; \mathrm{Cap}\left[0_{30} /([ \pm 45] \mathrm{s})_{5}\right]$

Figure 4 Schematic of Laminate Structure

Figure 5 Typical Duplicate Node Assignments

Figure 6 Fundamental Load Components

Figure 7 Axial Tension Load and Damage Progression

T300/Epoxy Laminate: Skin $\left[90 /\left([90 / \pm 15 / 90]_{s}\right)_{3}\right]_{s}$;

Web and toe $([ \pm 45] \mathrm{s})_{5} ; \operatorname{Cap}\left[0_{30} /([ \pm 45] \mathrm{s})_{5}\right]$

Figure 8 Response Degradation with Loading

T300/Epoxy Laminate: Skin $\left[90 /\left([90 / \pm 15 / 90]_{s}\right)_{3}\right]_{s}$;

Web and toe $([ \pm 45] \mathrm{s})_{5} ; \operatorname{Cap}\left[0_{30} /([ \pm 45] \mathrm{s})_{5}\right]$

Figure 9 Axial Compression Load and Damage Progression T300/Epoxy Laminate: Skin $\left[90 /\left([90 / \pm 15 / 90]_{s}\right)_{3}\right]_{s}$;

Web and toe $([ \pm 45] \mathrm{s})_{5} ; \operatorname{Cap}\left[0_{30} /([ \pm 45] \mathrm{s})_{5}\right]$

Figure 10 Displacement Contours under Axial Compression T300/Epoxy Laminate: Skin $\left[90 /\left([90 / \pm 15 / 90]_{s}\right)_{3}\right]_{9}$;

Web and toe $([ \pm 45] \mathrm{s})_{5} ; \operatorname{Cap}\left[0_{30} /([ \pm 45] \mathrm{s})_{5}\right]$

Figure 11 Shear Load and Damage Progression

T300/Epoxy Laminate: Skin $\left[90 /\left([90 / \pm 15 / 90]_{s}\right)_{3}\right]_{s}$;

Web and toe $([ \pm 45] \mathrm{s})_{5} ; \operatorname{Cap}\left[0_{30} /([ \pm 45] \mathrm{s})_{5}\right]$

Figure 12 Internal Pressure and Damage Progression

T300/Epoxy Laminate: Skin $\left[90 /\left([90 / \pm 15 / 90]_{s}\right)_{3}\right]_{s}$;

Web and toe $([ \pm 45] \mathrm{s})_{5} ; \operatorname{Cap}\left[0_{30} /([ \pm 45] \mathrm{s})_{5}\right]$ 


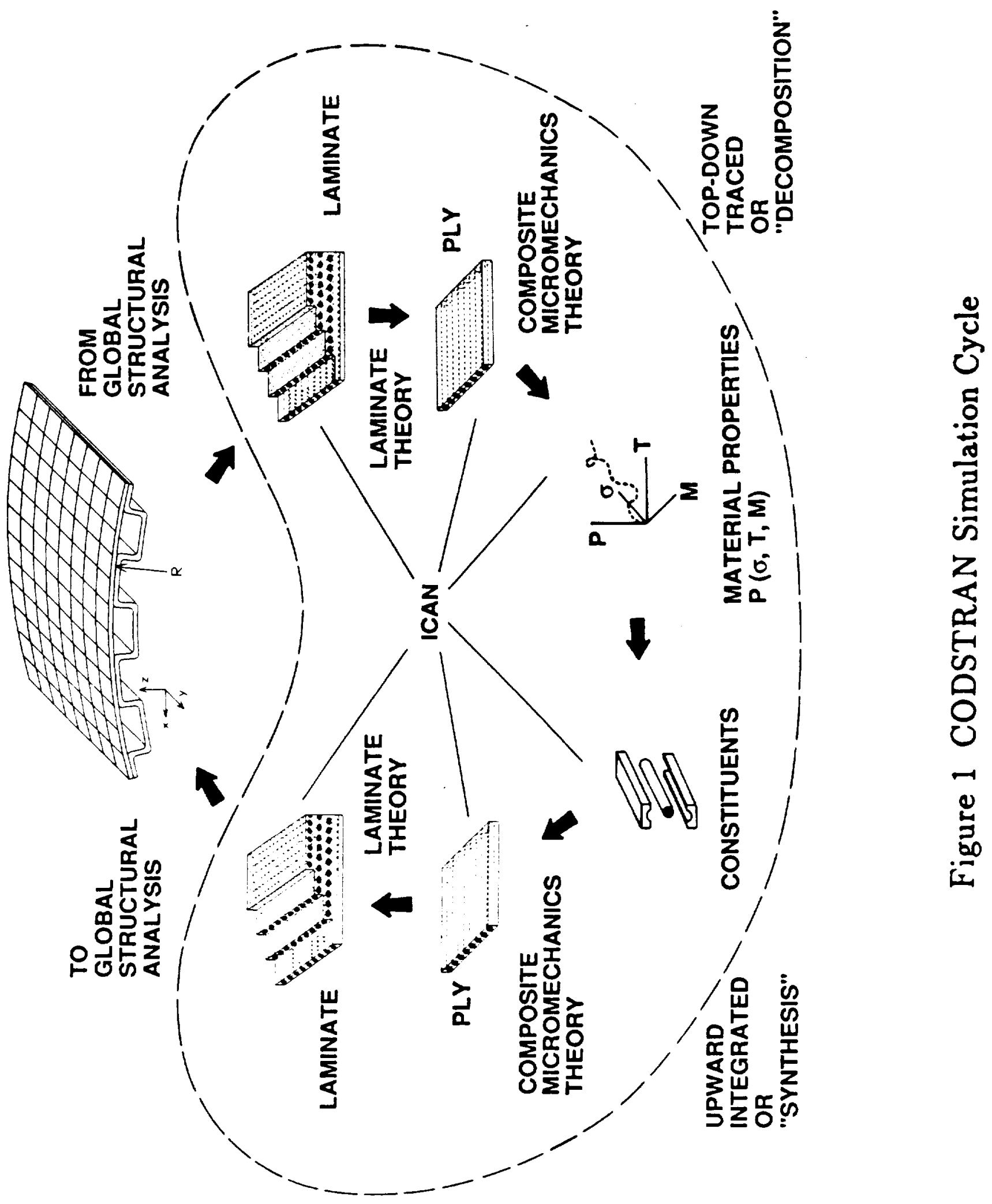




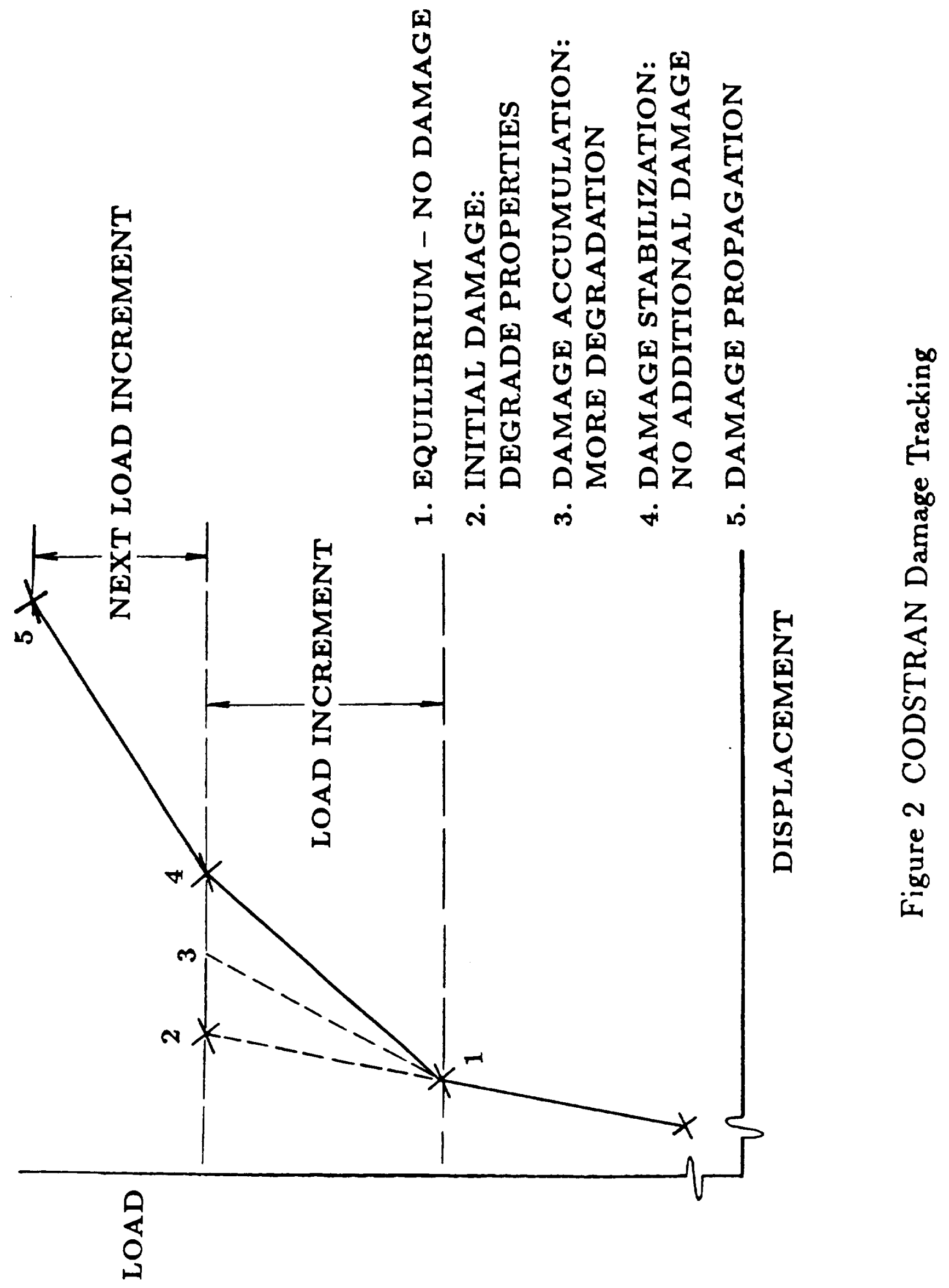




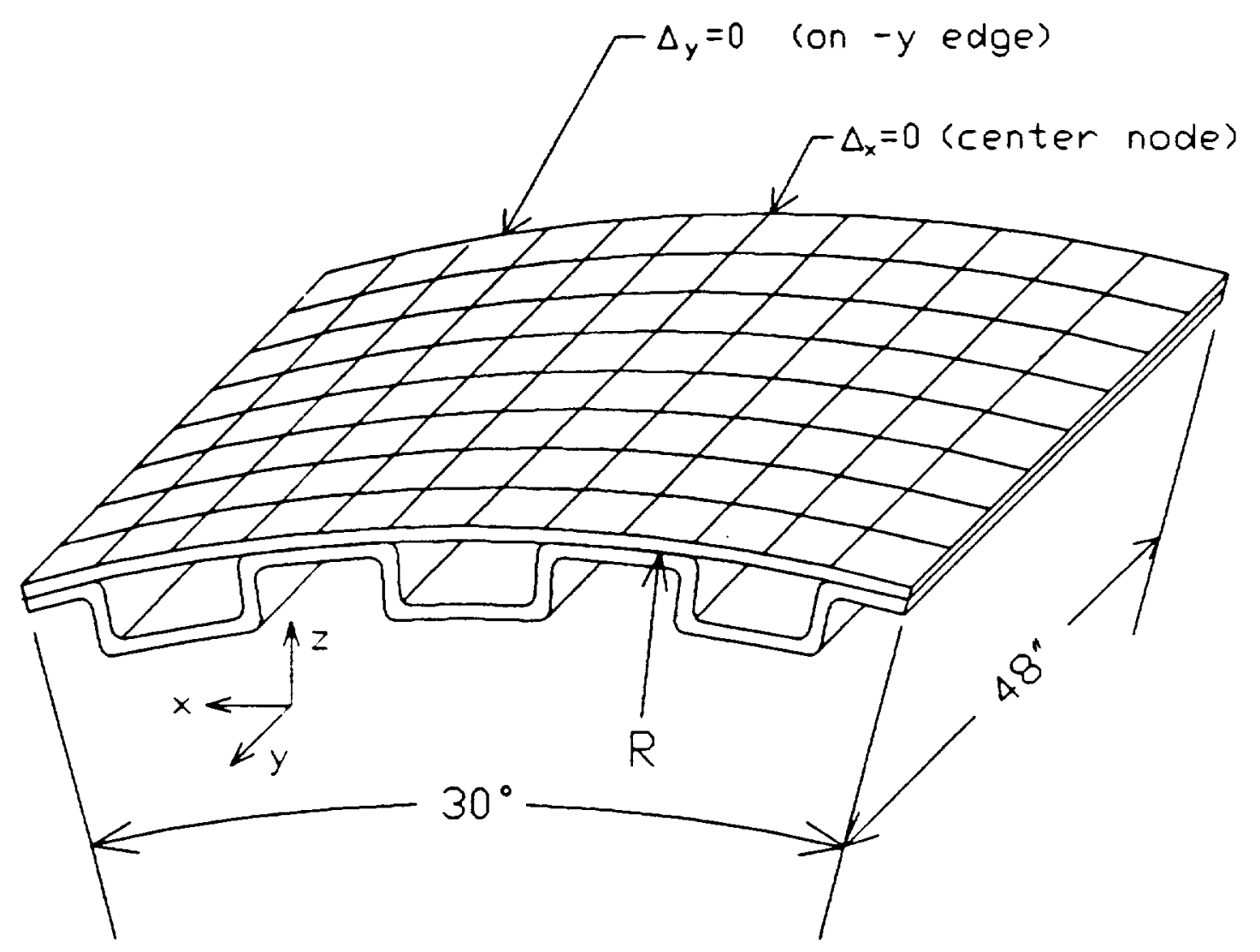

Figure 3 Stiffened Composite Cylindrical Shell Panel T300/Epoxy Laminate: Skin $\left[90 /\left([90 / \pm 15 / 90]_{s}\right)_{3}\right]_{s}$; Web and toe $([ \pm 45] \mathrm{s})_{5} ; \operatorname{Cap}\left[0_{30} /([ \pm 45] \mathrm{s})_{5}\right]$ 


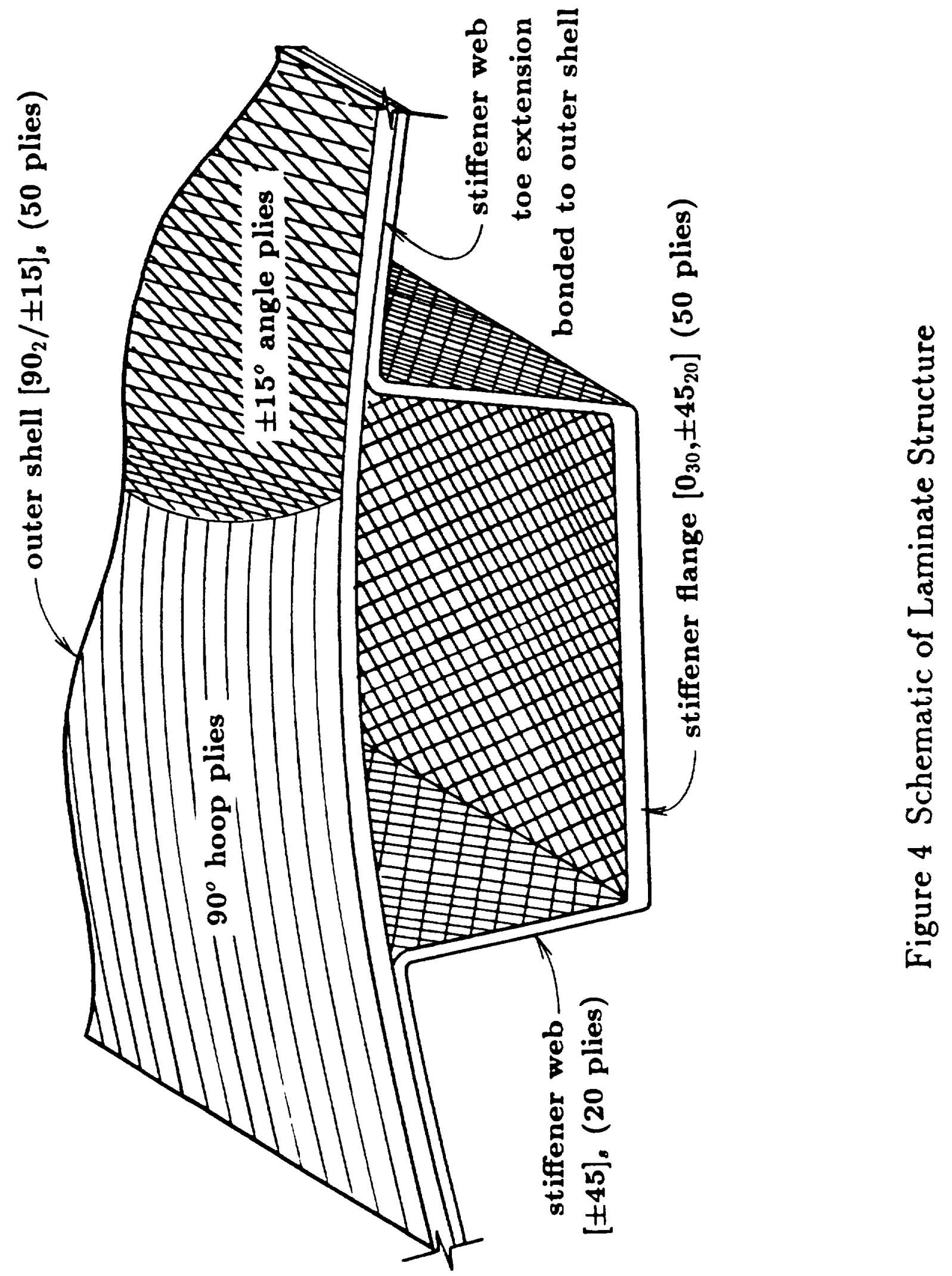




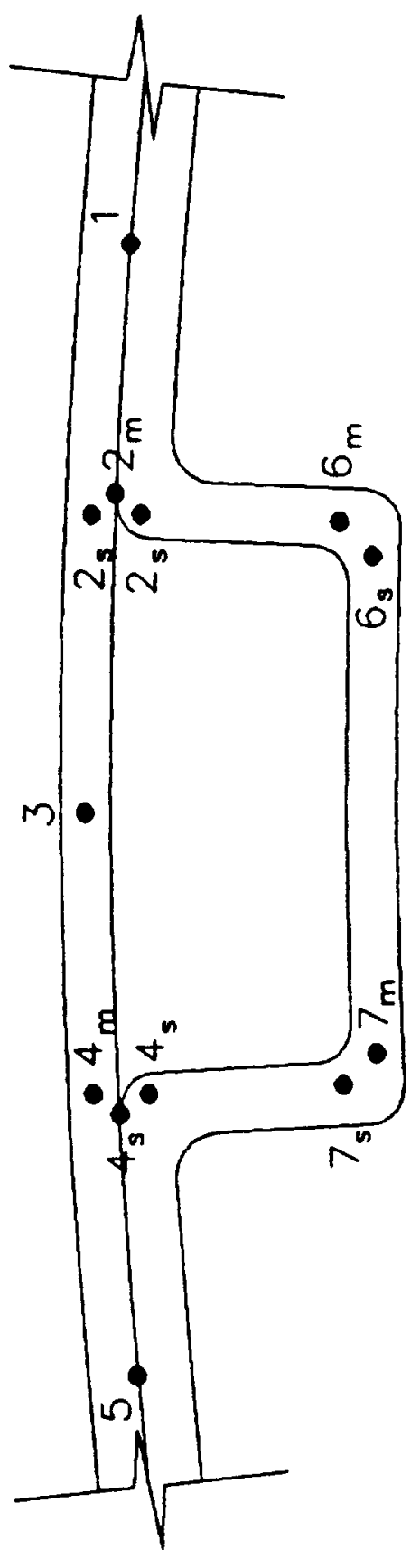

总 


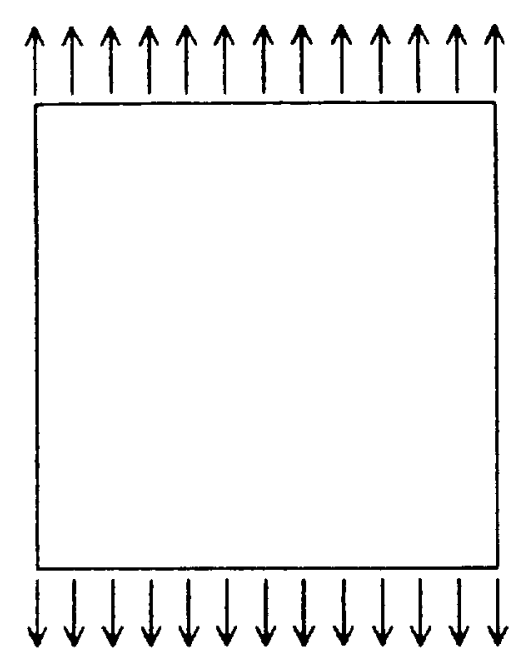

a) Axial Tension

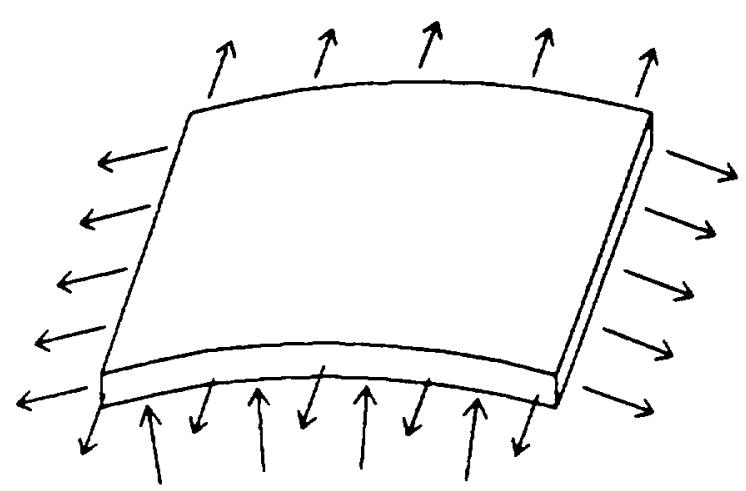

c) Internal Pressure

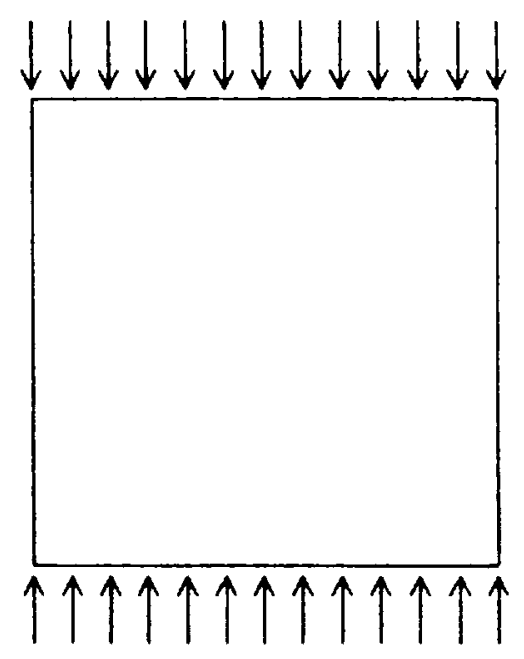

b) Axial Compression

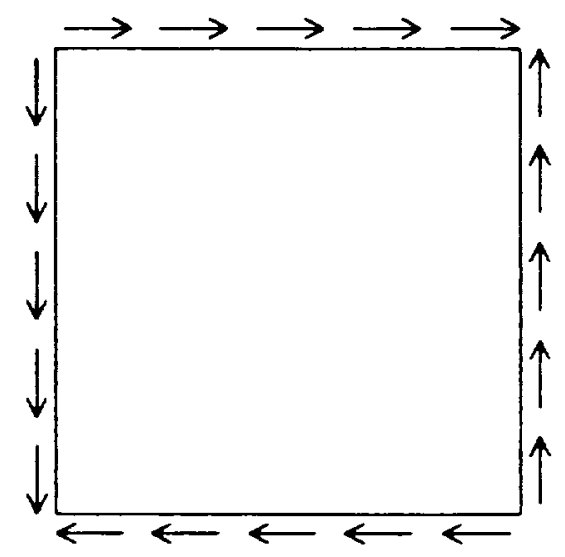

d) Sheor

Figure 6 Fundamental Load Components 


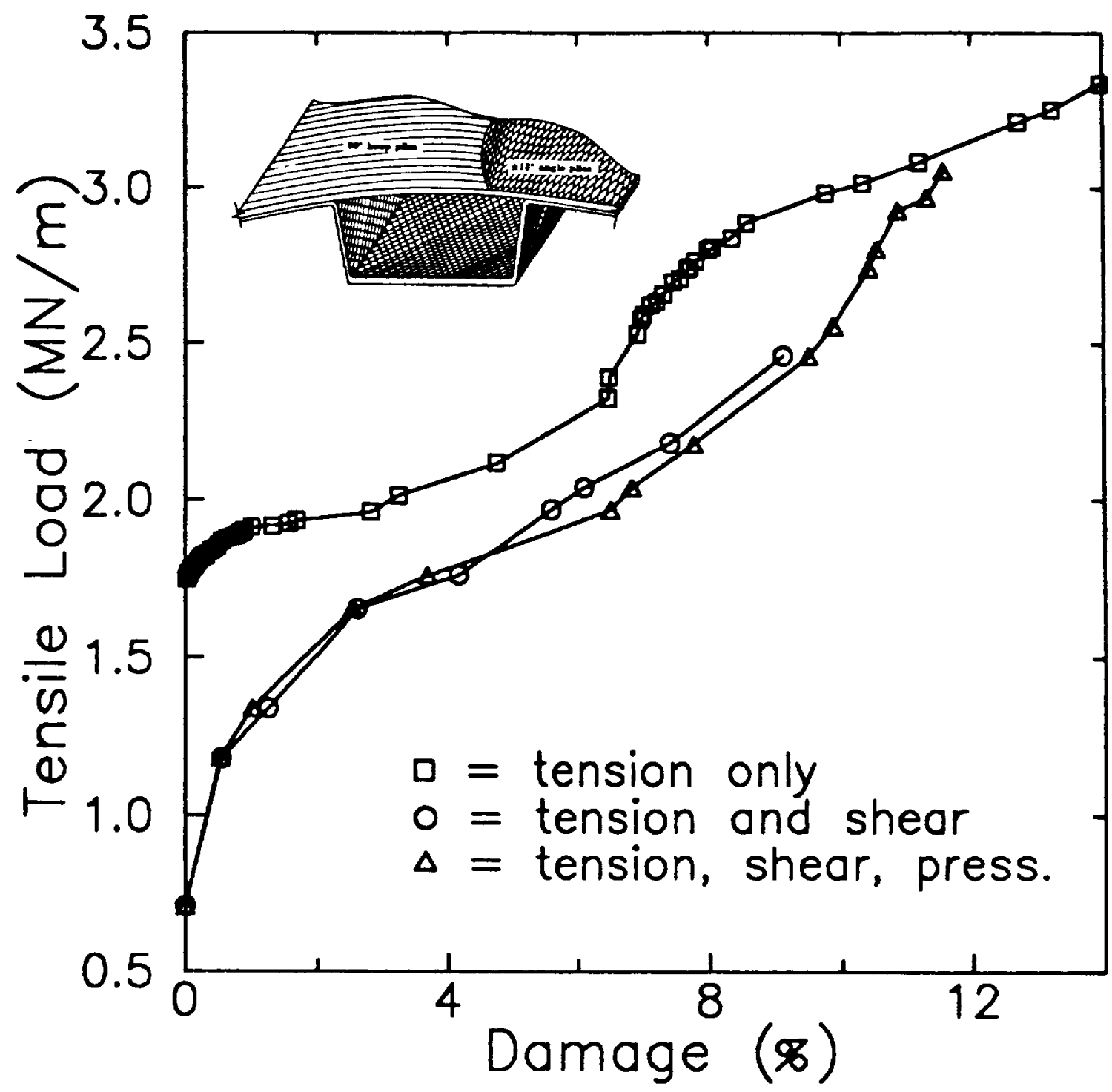

Figure 7 Axial Tension Load and Damage Progression T300/Epoxy Laminate: Skin $\left[90 /\left([90 / \pm 15 / 90]_{s}\right)_{3}\right]_{s}$; Web and toe $([ \pm 45] \mathrm{s})_{5} ; \mathrm{Cap}\left[0_{30} /([ \pm 45] \mathrm{s})_{5}\right]$ 


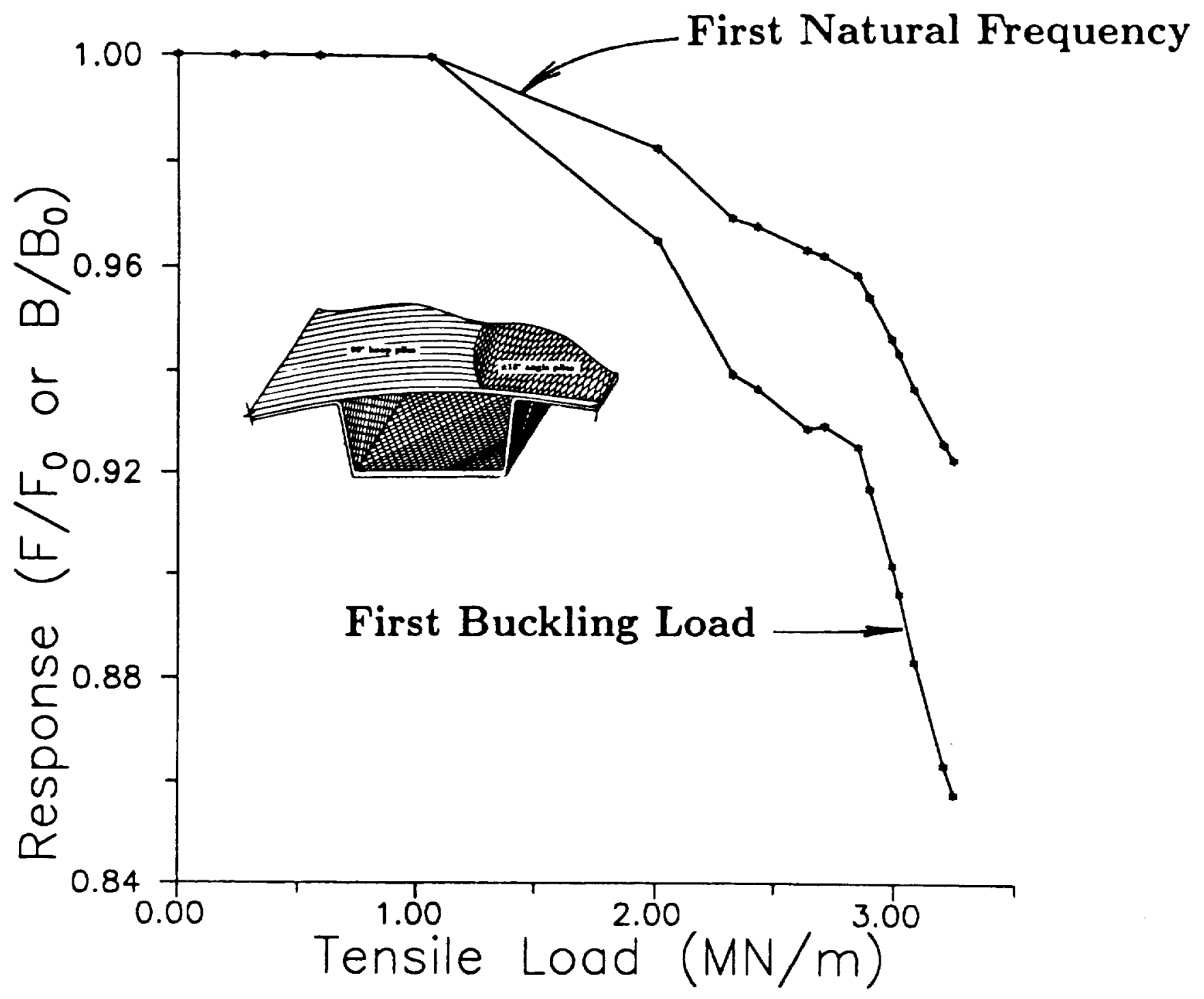

Figure 8 Response Degradation with Loading T300/Epoxy Laminate: Skin $\left[90 /\left([90 / \pm 15 / 90]_{s}\right)_{3}\right]_{s}$;

Web and toe $([ \pm 45] \mathrm{s})_{5} ; \operatorname{Cap}\left[0_{30} /([ \pm 45] \mathrm{s})_{5}\right]$ 